\title{
ACCURACY OF IMPLANT PLACEMENT USING TWO DIFFERENT TYPES OF CAD/CAM SURGICAL GUIDES (AN INVITRO STUDY)
}

\author{
Moustafa F. Ahmed ${ }^{1} B D S$, Ahmed M. AbdelHamid ${ }^{2} P h D$ \\ Fayza H. AlAbbasy ${ }^{3} P h D$
}

\begin{abstract}
INTRODUCTION: Computer-aided implant planning and guided surgery provide high accuracy to dental implant placement and facilitate more predictable prosthetic outcomes than non-guided implant surgery.

OBJECTIVES: To compare the accuracy of implant placement using 3D printed and machine milled surgical guides.

MATERIALS AND METHODS: Twelve polyurethane foam resin mandibular models were used in this study. Implant position was virtually planned using 3D planning software based on the preoperative CBCT of each model. Surgical guides were designed on the software and exported in STL format. Models were randomly divided into 2 groups ( $\mathrm{n}=6$ each). Group I: Surgical guides were manufactured using 3D printing. Group II: Surgical guides were manufactured using machine milling. Three implants were placed in each model using CAD/CAM surgical guides. The 3D position of the planned and placed implants, in terms of the linear deviations of the implant head and apex and the angular deviations of the implant axis, was compared by superimposing the pre- and postoperative CBCT using dedicated software. The MannWhitney $\mathrm{U}$ test was used for comparison $(\mathrm{P}<0.05)$.

RESULTS: The mean coronal, apical and angular deviation for Group I were $0.72 \pm 0.21 \mathrm{~mm}, 1.1 \pm 0.42 \mathrm{~mm}$ and $2.5^{\circ} \pm 1.2^{\circ}$ respectively, while for Group II they were $0.85 \pm 0.3 \mathrm{~mm}, 1.3 \pm 0.37 \mathrm{~mm}$ and $3.09^{\circ} \pm 0.89^{\circ}$ degrees respectively. No significant differences were found between both groups for any of the measurements.

CONCLUSIONS: 3D printing gave better results over machine milling; however, both types can be used in manufacturing surgical guides as difference in accuracy is not statistically significant. The accuracy of implants in both groups was within the safety margin of previous studies. KEYWORDS: CAD/CAM, surgical guides, 3D printing, computer guided surgery, CBCT, virtual planning
\end{abstract}

1- Bachelor of Dentistry, Faculty of Dentistry, Alexandria University, Egypt

2- Professor of Removable Prosthodontics, Faculty of Dentistry, Alexandria University, Egypt

3- Professor of Dental Biomaterials, Faculty of Dentistry, Alexandria University, Egypt

Corresponding author:

E-mail: airtifa@hotmail.com

\section{INTRODUCTION}

Dental implants have become a treatment option widely used for the replacement of lost teeth. The development of dental implants has had a major impact on the patients and the implant supported oral restoration has become an increasingly used treatment option for partially edentulous and completely edentulous patients (1).

Success in implant dentistry can no longer be limited to osseointegration and maintenance of alveolar bone. Osseointegration has shown success and high predictability in the literature repeatedly (2-4). Another criterion is implant placement that allow for fabrication of a crown or prosthesis with an esthetic appearance (5). Proper placement is among the critical factors in implant dentistry $(6,7)$.

Placement of implants has been planned and facilitated by means of simple periapical and panoramic radiographs for years (8). However, surgical templates have attracted a great deal of interest as a means to achieve more precise placement of implants at the surgical site because both the restorative plan (i.e., the biomechanical and esthetic requirements) and the internal anatomy (i.e., bone volume and position of vital structures) need to be taken into account $(9,10)$.

Surgical guide templates not only assist in diagnosis and treatment planning but also facilitate proper positioning and angulation of the implants in the bone (11). Moreover, restoration driven implant placement accomplished with a surgical guide template can decrease clinical and laboratory complications (12). Hence, increasing demand for dental implants has resulted in the development of newer and advanced techniques for the fabrication of these templates (13).

Traditionally, two-dimensional imaging and a guide made on the dental cast, also known as a conventional surgical guide, were used to assist in proper surgical placement and angulation. More recently, cone beam computerized tomography (CBCT) has gained popularity and is routinely used in the planning process (14).

Conventional surgical guides are made in the dental laboratory on casts generated from impressions and have been used routinely for the placement of dental implants. However, during implant placement, conventional surgical guides allow for potential clinician-mediated positioning errors due to inadvertent angular and linear deviations during osteotomy or drilling sequences, reducing the degree of accuracy (15).

Computer-aided design/computer-aided manufacturing (CAD/CAM) allows the production of surgical guides that are virtually planned and designed using data accrued from 3D imaging utilizing computer software and digital workflow for planning and manufacturing. They have metallic sleeves that direct and allow precise implant placement in the $\mathrm{x}, \mathrm{y}$ and $\mathrm{z}$ axes. CBCT scanning and digital 
imaging techniques, which allow visualization of the placement of dental implants in three dimensions, have gained popularity in their applications given their ability to achieve predictable and accurate results (16).

Use of such a system usually removes complications including mandibular nerve damage, sinus perforations, fenestrations or dehiscences. The dentist can now simulate ideal implant placement and treatment planning that includes the precise dimensions of the implant, the ideal depth, and angulation made on the CBCT scans. In addition, this improved precision and accuracy reduces the need for flap reflection (17).

CAD/CAM uses different approaches for manufacturing, subtractive manufacturing is usually accomplished by the Computer Numerical Controlled (CNC) machining, creating objects by progressive removal or deformation of material (drilling, cutting, bending) from a large block or sheet in the form of chips (18). While additive manufacturing or $3 \mathrm{D}$ printing is a manufacturing method in which objects are made by fusing or depositing materials - such as plastic, metal, ceramics, powders, liquids, or even living cells - in layers to produce a 3D object (19).

Template-guided implant surgery requires preoperative steps, starting with fabrication of a radiographic template, CBCT acquisition with the template in position, computer assisted implant planning and ending in fabrication and use of a surgical guide for drilling and implant insertion. With such a complex sequence, where every step is prone to errors, accuracy is of utmost importance (20).

The purpose of this study was to compare the accuracy of implant placement using 3D printed surgical guides and machine milled surgical guides. The null hypotheses was that there is no difference in angular deviation, deviation at the head, or deviation at the apex of implants placed using 3D printed and milled surgical guides.

\section{MATERIALS AND METHODS}

Twelve identical mandibular Kennedy Class I partially edentulous polyurethane foam resin models (Hann Ru Co. Ltd., Taiwan) were selected for the study (Figure 1).

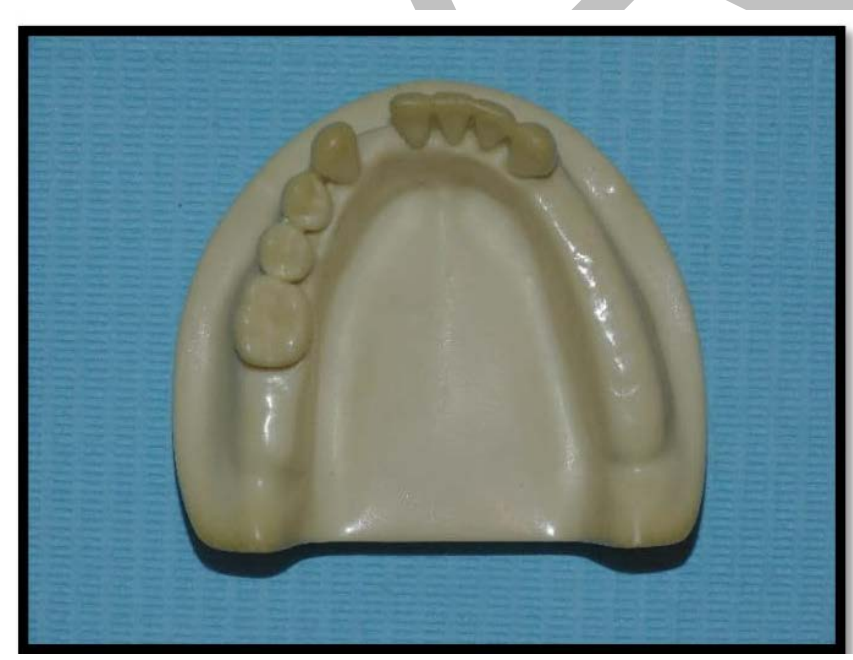

Figure 1: Polyurethane Foam resin model

Preoperative low-dose, high-resolution Cone Beam Computer Tomography (CBCT) scans of the models were performed at a proper field of view. The scan setting used was $8 \mathrm{~mA}$ and $90 \mathrm{KV}$ with $0.1 \mathrm{~mm}$ in voxel size (Scanora ${ }^{\circledR}$ 3Dx, Soredex, Helsinki, Finland).

The DICOM (Digital Imaging and Communications in Medicine) file obtained from the CBCT was imported to the virtual planning software (OnDemand3D, Cybermed Inc., Seoul, Korea). Virtual placement of three implants at the right first and second premolars and first molar was done so that the distance between each two implants is $3 \mathrm{~mm}$ while the distance between tooth and implant is $1.5 \mathrm{~mm}$. The placement was then evaluated in the sagittal plane, horizontal plane, and the three dimensional rendering (Figure 2).

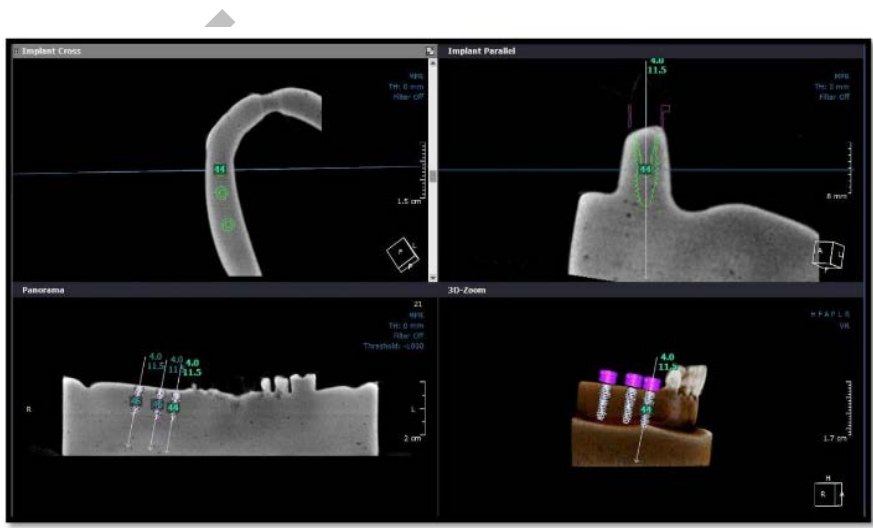

Figure 2: Virtual implant placement

The outline of the surgical guide was then drawn on the model and converted into 3D guide. Then finally the designed guide was saved in STL format.

The models were randomly divided into two main groups with six models each according to the type of surgical guide manufacturing. Group I: Surgical guides were manufactured using $3 \mathrm{D}$ printing (additive manufacturing). Group II: Surgical guides were manufactured using machine milling (subtractive manufacturing).

In Group I: The STL file of the surgical guide for each model was fabricated from a special clear resin material (Eguide 600, Envisiontec GmbH, Gladbeck, Germany) by 3D printer (Envisiontec DDDP, Envisiontec GmbH, Gladbeck, Germany) using Digital Light Processing (DLP) technology.

In Group II: The STL file of the surgical guide for each model was milled from a clear Polymethylmethacrylate (PMMA) disc (Copratemp, Whitepeaks Dental Solutions GmbH \& Co. KG, Germany) using a 5-axis milling machine (Shera Eco-Mill 5X; Shera Werkstoff Technologie, Germany).

Three titanium sleeves where attached to each surgical guide using cyanoacrylate corresponding to each implant position to control the direction and depth of drilling. In2Guide Universal kit (Cybermed Inc., Seoul, Korea) was used which is a 44-piece surgery kit, specifically designed for In2Guide surgical templates to perform full sequence drilling. Surgical guide was placed onto the model and checked for stability and fit (Figure 3). 


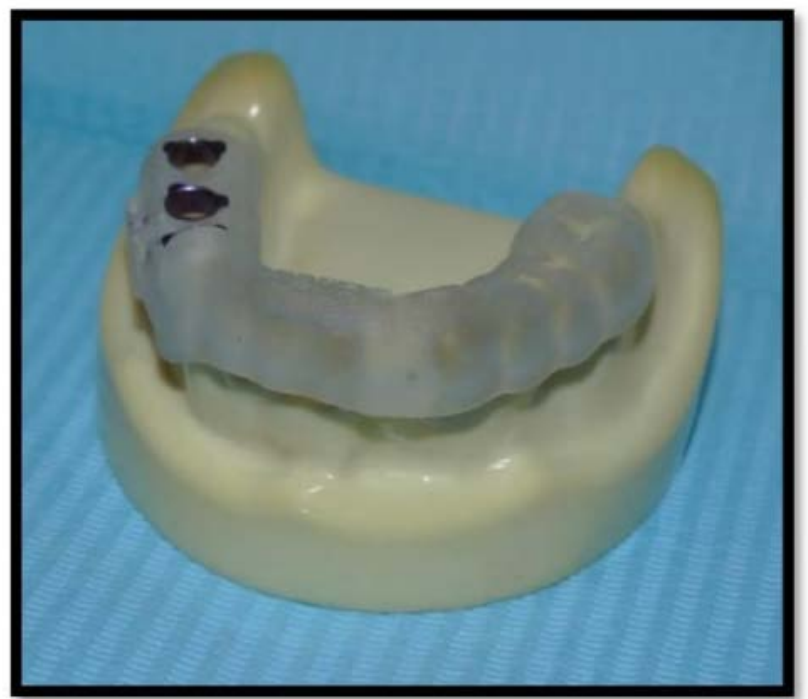

Figure 3: Surgical Guide adapted to the model

A pilot key with a diameter of $2 \mathrm{~mm}$ was placed within the sleeve hole of the surgical guide to match the diameter of the pilot drill and pilot hole was drilled into the model using surgical torque control motor $\left(\mathrm{W} \& \mathrm{H}^{\circledR}\right.$ Implantmed; W\&H Dentalwerk Bürmoos GmbH, Bürmoos, Austria) at $1200 \mathrm{rpm}$.

Then sequential drilling was done using specific keys corresponding to the drills size $(2.5 ; 3.3$; to reach a diameter of 3.5 for implant installation). Three dummy dental implants (OXY, Biomec SRL, Colico, Italy) with diameter $4 \mathrm{~mm}$ and length $11.5 \mathrm{~mm}$ were placed in each model using manual torque wrench at $40 \mathrm{Ncm}$.

Postoperative Cone Beam Computer Tomography (CBCT) scans of the models were performed with the same apparatus and settings as the preoperative scans.

The preoperative (implant planning) and postoperative (achieved implant position) scans were then overlapped using a dedicated algorithm, which allowed the comparison of the virtually planned and the actual implant positions. Three deviation parameters between each planned and placed implant were measured. All measurements were performed using dedicated software (OnDemand3D, Cybermed Inc., Seoul, Korea) (Figure 4).

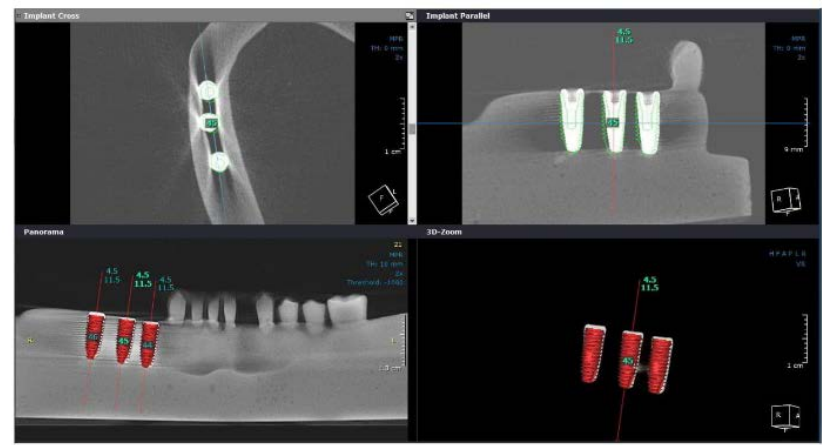

Figure 4: Superimposition of pre- and postoperative scans and evaluation of accuracy

For analysing the accuracy, the planned position of the implant was compared with the actual position of the implant after insertion. Several measuring points were used for the comparison of these positions:
1. Coronal deviation (mm), frequently defined as the horizontal or vertical (depth) distances between the midaxial coronal point of the planned implant and that of the placed implant position.

2. Apical deviation $(\mathrm{mm})$, frequently defined as the horizontal or vertical distances between the midaxial apical point of the planned implant and that of the placed implant position.

3. Angular deviation $\left({ }^{\circ}\right)$, frequently defined as the angular difference of the axial projections of both virtual and final implant placements.

Though several methods were used to describe the distance between the given points, the most common method was to measure the actual distance between the planned and actual point in the $\mathrm{x}, \mathrm{y}$, and $\mathrm{z}$-axis, where $\mathrm{x}=$ bucco-lingual, $\mathrm{y}=$ mesio-distal, and $\mathrm{z}=$ apico-coronal deviation. The 3D deviation was calculated by the software using Pythagorean Theorem (21): (Figure 5)

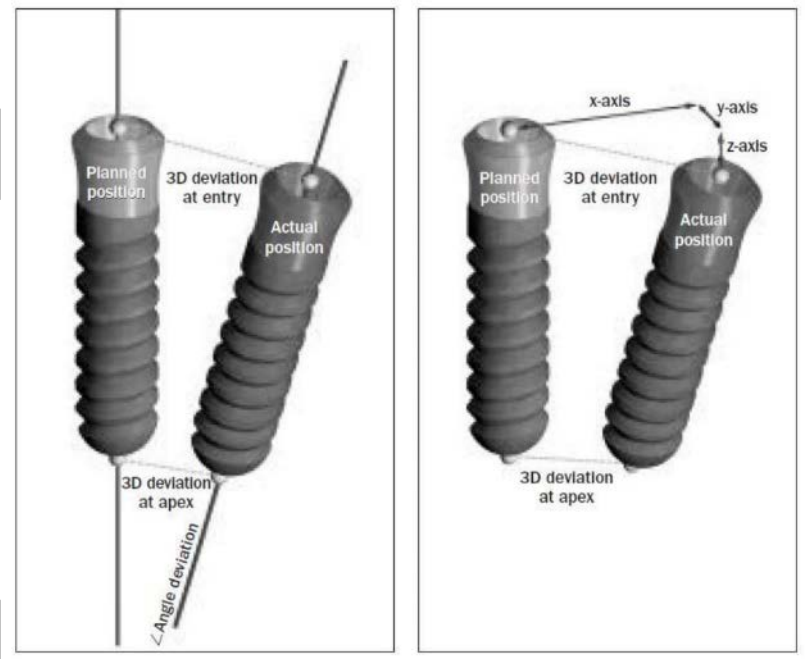

Figure 5: Different variables for describing the deviations

$3 \mathrm{D}$ dev. $=\sqrt{ }\left(\mathrm{x}^{\wedge} 2+\mathrm{y}^{\wedge} 2+\mathrm{z}^{\wedge} 2\right)$

Statistical analysis:

Data were analyzed statistically using a computerized statistical software program (IBM SPSS software package version 23.0 (SPSS Inc., Chicago, IL, USA)). The Kolmogorov-Smirnov test showed that the data were distributed non-parametrically. Therefore, a Mann-Whitney $\mathrm{U}$ test was used for comparisons between planned and placed implants in terms of angular deviation and the position of the implant at the neck and apex. Differences were considered statistically significant if $\mathrm{p}$ was less than .05. Box Plots were used for graphical presentation.

\section{RESULTS}

In this study, 36 implants were placed in twelve polyurethane foam models (three implants in each model). Of these, 18 were placed using 3D printed surgical guides and 18 were placed using milled surgical guides.

The angular deviations of the placed implants in group I and II were $2.5^{\circ} \pm 1.2^{\circ}$ and $3.09^{\circ} \pm 0.89^{\circ}$ respectively. The mean coronal and apical deviations in distance between the planned and placed implants were $0.72 \pm 0.21 \mathrm{~mm}$ and 1.1 $\pm 0.42 \mathrm{~mm}$ for Group I; $0.85 \pm 0.3 \mathrm{~mm}$ and $1.3 \pm 0.37 \mathrm{~mm}$ for Group II respectively. Mean apical, coronal and angular deviations in Group I were smaller than that of Group II, 
although it did not reach a significant level ( $p>0.05$ ). (Table 1 and Figure 6)

For all 36 implants, the mean angular deviation of the long axis between the planned and placed implants was $2.79^{\circ} \pm 1.08^{\circ}$; the mean coronal and apical deviations in distance between the planned and placed implants were 0.79 $\pm 0.26 \mathrm{~mm}$ and $1.2 \pm 0.4 \mathrm{~mm}$ respectively.

Table (1): Summarized results of measured linear and angle deviations as well as significance calculation:

\begin{tabular}{|c|c|c|c|c|}
\hline & $\begin{array}{c}\text { Group I } \\
(\mathrm{n}=18)\end{array}$ & $\begin{array}{c}\text { Group II } \\
(\mathrm{n}=18)\end{array}$ & $\mathrm{U}$ & $\mathrm{p}$ \\
\hline $\begin{array}{c}\text { Angular deviation } \\
\left({ }^{\circ}\right)\end{array}$ & $0.5-$ & $1.7-4.7$ & & \\
Min. - Max. & 4.40 & $3.09 \pm$ & 107.0 & $0.082^{\mathrm{ns}}$ \\
Mean \pm SD & $2.5 \pm 1.2$ & 0.89 & & \\
Median & 2.2 & 2.99 & & \\
\hline $\begin{array}{c}\text { Coronal deviation } \\
(\mathbf{m m})\end{array}$ & $0.44-$ & $0.43-$ & & \\
Min. - Max. & 1.18 & 1.35 & 124.0 & $0.229^{\mathrm{ns}}$ \\
Mean \pm SD & $0.72 \pm$ & $0.85 \pm$ & & \\
Median & 0.21 & 0.3 & & \\
& 0.68 & 0.79 & & \\
Apical deviation & & & & \\
$(\mathbf{m m})$ & $0.47-$ & $0.91-$ & & \\
Min.- Max. & 2.06 & 2.15 & 122.0 & $0.206^{\mathrm{ns}}$ \\
Mean \pm SD & $1.1 \pm$ & $1.3 \pm$ & & \\
Median & 0.42 & 0.37 & & \\
& 1.03 & 1.15 & & \\
\hline
\end{tabular}

$\mathrm{U}, \mathrm{p}$ : $\mathrm{U}$ and $\mathrm{p}$ values for Mann Whitney test for comparing between both groups

ns Not significant as $\mathrm{P}>0.05$

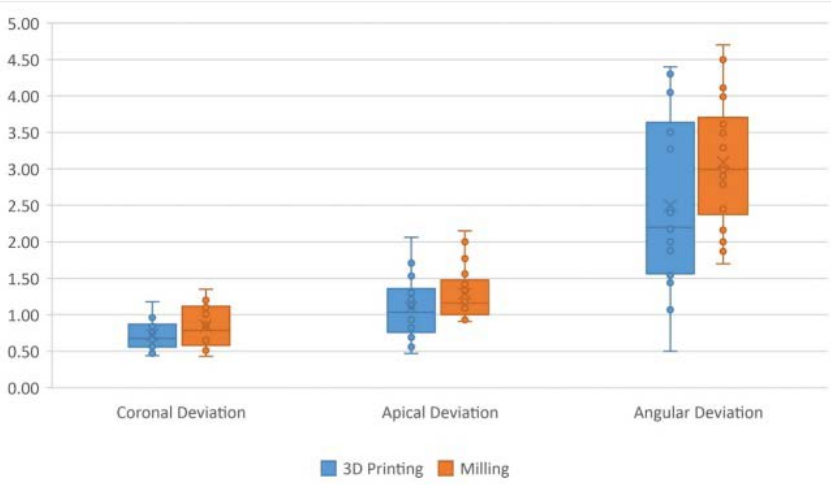

Figure 6: Box plots showing median quartile and extreme values (depicted as dot outliers) for angular deviations of implants placed using 3D printing and machine milling

\section{DISCUSSION}

Computed tomography is a helpful tool for implant patients, especially for situations with anatomical limitations, insufficient bone dimensions, and poor bone density (22). The use of CT imaging enhances the correlation between implant planning and actual implant placement compared with conventional radiographic methods (14). The introduction of computer-aided manufacturing (CAM) of anatomic models and surgical guides generated from computer-aided design (CAD) images has accurately allowed the transfer of planning information to implant placement. For implant planning and placement, the association of CAD and CAM techniques furnishes some advantages, regarding 3D determination of the patient's jaw anatomy and fabrication of both anatomical models and surgical guides (23).
The template-guided surgery concept involves many processes that result in deviations between the planned and the clinically placed implant positions. The overall accuracy of the implant placement is the sum of all errors that arise during the whole treatment procedure. Although it is difficult to detect deviations that possibly occur in each step, it is essential for clinicians to learn to what extent the deviations occur between the virtually planned implant positions and positions of clinically placed implants, in order to avoid anatomical risks as well as for the final prosthetic reconstruction. The accuracy is also a great matter of concern, especially in the case of immediate delivery of a prefabricated prosthesis $(24,25)$.

The present study was conducted to evaluate the accuracy of implant placement by using CAD/CAM surgical guides fabricated by $3 \mathrm{D}$ printing and Machine milling techniques.

Tooth supported surgical guide was selected for the study as the accuracy of implant placement with the use of tooth-supported surgical guides is reportedly superior to that with the use of bone- and mucosa-supported guides $(17,26,27)$.

Polyurethane foam resin models were selected for its structure and its close resemblance to natural bone that duplicates type II $\sim$ III hardness to simulate drilling in natural bone before implant placement. It had elastic characteristics as well as physical and mechanical characteristics similar to those found in human bone $(28,29)$.

In2Guide ${ }^{\mathrm{TM}}$ software was the software of choice. It provided the facility of construction of 3D images, accurate and easier superimposition than other softwares and easy angular measurements. Surgical guide was completely designed by In2Guide ${ }^{\mathrm{TM}}$ and exported directly as STL file for prototyping (30).

Digital Light Processing (DLP) technology used for 3D printing in this study has advantages over stereolithography (SLA) which is the most common technology used in dental field, DLP achieves quicker print times for most parts. The reason it is faster is that it exposes entire layers at once. With SLA printing, a laser has to draw out each of these layers, and this takes time. Also it gives good accuracy, smoother surfaces and more economical (31).

In our present study - for both groups - the mean coronal, apical and angular deviations were $0.79 \mathrm{~mm}, 1.2 \mathrm{~mm}$ and $2.79^{\circ}$ respectively. Van Assche et al (32) conducted a systematic review to assess the accuracy of static surgical guides, it showed that the mean error was $0.99 \mathrm{~mm}$ at the coronal center, $1.24 \mathrm{~mm}$ at the apical center, and the axis deviation was $3.81^{\circ}$. Turbush et al (27) also conducted an invitro study comparing the accuracy of various surgical guides. In that study, the mean error was $1 \mathrm{~mm}$ at the coronal center and $1.15 \mathrm{~mm}$ at the apical center and the axis deviation was $2.26^{\circ}$. Thus, the results of the deviation measurements in this study are consistent with the findings of previous studies.

On the contrary, few studies showed higher deviations as Giacomo et al (33) which showed mean coronal, apical and angular deviation of $1.45 \mathrm{~mm}, 2.99 \mathrm{~mm}$ and $7.25^{\circ}$ respectively. The authors attributed these deviations to micro-movements of the surgical guide caused by neglecting using screws to stabilize the surgical guide in cases of bone-supported guide. Also, Vieira et al (34) compared the accuracy between maxilla and mandible and 
found higher deviations in the maxilla due to due to the lower bone density of the maxilla, which is more susceptible to transfer inaccuracies than the compact mandibular bone.

Inaccuracies of $3 \mathrm{D}$ printing compared to milling is attributed the need for supporting structure and post curing cycle. While for the milling protocol of PMMA was very sensitive due to the excessive hardness of the material that in reverse increased the pressure of cutting that might lead to thermal stresses and distortion of the material. Also cutting conditions might cause excessive vibration that could exert more thermal and mechanical stresses on the work piece especially in areas with thin thickness during the procedure (35).

It is worth noting that the length, angle, and proper position of an implant play critical roles in the placement procedure. The results of the present study found that the apical deviation between the planned and actual implant position was $1.1 \mathrm{~mm}$ and $1.3 \mathrm{~mm}$ for group I and II respectively, appreciably less than the well-known standard "safety zone" of 2 mm away from vital structures $(36,37)$.

Furthermore, according to the data indicated in Table 1, the accuracy of angle and position was reasonably appropriate. The clinical importance of these results may be relevant in such situations when multiple parallel but distant implants are placed, and where the degree of accuracy is critical for prosthetic restoration. Replacement of removable wearing parts could be reduced by the use of more accurate surgical implant placement. Unfortunately, there is no available data in the literature on the accuracy of the milled surgical guides.

The results of this study confirm the null hypothesis that there is no difference in the accuracy of implant angulations, implant head and implant apex when using a 3D printed surgical guide compared with a milled surgical guide.

\section{CONCLUSION}

Within the limitations of this invitro study, the following conclusions can be drawn:

1- 3D printing (additive manufacturing) gave better results over machine milling (subtractive manufacturing); however, both types can be used in manufacturing surgical guides as difference in accuracy is not statistically significant.

2- The accuracy of implant placement in both groups was within the safety margin of previous studies.

3- The total accuracy represents the sum of all cumulative errors throughout the computer-aided implant placement cascade and errors can arise at different stages, the clinician should check for perfect adaptation of surgical guide before beginning of treatment, as well as during surgery.

\section{CONFLICT OF INTEREST}

The authors declare that they have no conflicts of interest.

\section{ACKNOWLEDGMENTS:}

I would like to extend my gratitude to Ahmed Moubarak and Nayrouz Adel for their great help and support.

\section{REFERENCES}

1. Widmann G, Bale RJ. Accuracy in computer-aided implant surgery--a review. Int. J. Oral Maxillofac. Implants 2006;21:305-13.
2. Adell R, Lekholm U, Rockler B, Brånemark PI. A 15year study of osseointegrated implants in the treatment of the edentulous jaw. Int. J. Oral Surg. 1981;10:387416.

3. Albrektsson T, Zarb G, Worthington P, Eriksson AR. The long-term efficacy of currently used dental implants: a review and proposed criteria of success. Int. J. Oral Maxillofac. Implants 1986;1:11-25.

4. Adell R, Eriksson B, Lekholm U, Brånemark PI, Jemt T. Long-term follow-up study of osseointegrated implants in the treatment of totally edentulous jaws. Int. J. Oral Maxillofac. Implants 1990;5:347-59.

5. lbrektsson $T$. On long-term maintenance of the osseointegrated response. Aust. Prosthodont. J. Aust. Prosthodont. Soc. 1993;7 Suppl:15-24.

6. Goodacre CJ, Bernal G, Rungcharassaeng K, Kan JYK. Clinical complications with implants and implant prostheses. J. Prosthet. Dent. 2003;90:121-32.

7. Binon PP. Treatment planning complications and surgical miscues. J. Oral Maxillofac. Surg. Off. J. Am. Assoc. Oral Maxillofac. Surg. 2007;65:73-92.

8. Kopp KC, Koslow AH, Abdo OS. Predictable implant placement with a diagnostic/surgical template and advanced radiographic imaging. J. Prosthet. Dent. 2003;89:611-5.

9. Fortin T, Champleboux G, Lormée J, Coudert JL. Precise Dental Implant Placement in Bone Using Surgical Guides in Conjunction With Medical Imaging Techniques. J. Oral Implantol. 2000;26:300-3.

10. C. M. Dental Implant Prosthetics, 2e. 1 edition. St. Louis, Mo.: Mosby; 2014.

11. Park C, Raigrodski AJ, Rosen J, Spiekerman C, London RM. Accuracy of implant placement using precision surgical guides with varying occlusogingival heights: an in vitro study. J. Prosthet. Dent. 2009;101:372-381.

12. Garber DA, Belser UC. Restoration-driven implant placement with restoration-generated site development. Compend. Contin. Educ. Dent. Jamesburg NJ 1995 1995;16:796, 798-802, 804.

13. D’Souza KM, Aras MA. Types of Implant Surgical Guides in Dentistry: A Review. J. Oral Implantol. 2012;38:643-52.

14. Benavides E, Rios HF, Ganz SD, An C-H, Resnik R, Reardon GT, et al. Use of cone beam computed tomography in implant dentistry: the International Congress of Oral Implantologists consensus report. Implant Dent. 2012;21:78-86.

15. Belser UC, Schmid B, Higginbottom F, Buser D. Outcome analysis of implant restorations located in the anterior maxilla: a review of the recent literature. Int. J. Oral Maxillofac. Implants 2004;19 Suppl:30-42.

16. Farley NE, Kennedy K, McGlumphy EA, Clelland NL. Split-mouth comparison of the accuracy of computergenerated and conventional surgical guides. Int. J. Oral Maxillofac. Implants 2013;28:563-72.

17. Ozan O, Turkyilmaz I, Ersoy AE, McGlumphy EA, Rosenstiel SF. Clinical Accuracy of 3 Different Types of Computed Tomography-Derived Stereolithographic 
Surgical Guides in Implant Placement. J. Oral Maxillofac. Surg. 2009;67:394-401.

18. Masri R, Driscoll CF, editors. Clinical applications of digital dental technology. Ames, Iowa: John Wiley and Sons Inc; 2015.

19. Ventola CL. Medical applications for 3D Printing: current and projected uses. Pharm. Ther. 2014;39:704.

20. Horwitz J, Zuabi O, Machtei EE. Accuracy of a computerized tomography-guided template-assisted implant placement system: an in vitro study. Clin. Oral Implants Res. 2009;20:1156-62.

21. Tahmaseb A, Wismeijer D, Coucke W, Derksen W. Computer technology applications in surgical implant dentistry: a systematic review. Int. J. Oral Maxillofac. Implants 2014;29 Suppl:25-42.

22. Siessegger M, Schneider BT, Mischkowski RA, Lazar F, Krug B, Klesper B, et al. Use of an image-guided navigation system in dental implant surgery in anatomically complex operation sites. J. CranioMaxillo-fac. Surg. Off. Publ. Eur. Assoc. CranioMaxillo-fac. Surg. 2001;29:276-81.

23. Beuer F, Schweiger J, Edelhoff D. Digital dentistry: an overview of recent developments for CAD/CAM generated restorations. Br. Dent. J. 2008;204:505-11.

24. Vercruyssen M, Laleman I, Jacobs R, Quirynen M. Computer-supported implant planning and guided surgery: a narrative review. Clin. Oral Implants Res. 2015;26:69-76.

25. Komiyama A. Evaluation of computer-assisted virtual treatment planning and template-guided surgery in dental implant treatment. 2010;

26. Geng W, Liu C, Su Y, Li J, Zhou Y. Accuracy of different types of computer-aided design/computeraided manufacturing surgical guides for dental implant placement. Int. J. Clin. Exp. Med. 2015;8:8442.

27. Turbush SK, Turkyilmaz I. Accuracy of three different types of stereolithographic surgical guide in implant placement: an in vitro study. J. Prosthet. Dent. 2012;108:181-188.

28. Miyashiro M, Suedam V, Moretti Neto RT, Ferreira PM, Rubo JH. Validation of an experimental polyurethane model for biomechanical studies on implant supported prosthesis - tension tests. J. Appl. Oral Sci. 2011;19:244-8.

29. Lee J-H, Kim S-M, Paeng J-Y, Kim M-J. Implant surgery based on computer simulation surgical stent and the assessment with the image fusion technique. J. Korean Assoc. Oral Maxillofac. Surg. 2010;36:402-7.

30. Moon S-Y, Lee K-R, Kim S-G, Son M-K. Clinical problems of computer-guided implant surgery. Maxillofac. Plast. Reconstr. Surg. 2016;38:15.

31. Azari A, Nikzad S. The evolution of rapid prototyping in dentistry: a review. Rapid Prototyp. J. 2009;15:216225.

32. Van Assche N, Vercruyssen M, Coucke W, Teughels W, Jacobs R, Quirynen M. Accuracy of computer-aided implant placement. Clin. Oral Implants Res. 2012;23:112-23.

33. Giacomo GAPD, Cury PR, Araujo NS de, Sendyk WR, Sendyk CL. Clinical Application of Stereolithographic Surgical Guides for Implant Placement: Preliminary Results. J. Periodontol. 2005;76:503-7.

34. Vieira DM, Sotto-Maior BS, Barros CAV de S, Reis ES, Francischone CE. Clinical accuracy of flapless computer-guided surgery for implant placement in edentulous arches. Int. J. Oral Maxillofac. Implants 2013;28:1347-51.

35. Abduo J, Lyons K, Bennamoun M. Trends in ComputerAided Manufacturing in Prosthodontics: A Review of the Available Streams. Int. J. Dent. 2014;2014:e783948.

36. Valente F, Schiroli G, Sbrenna A. Accuracy of computer-aided oral implant surgery: a clinical and radiographic study. Int. J. Oral Maxillofac. Implants 2009;24:234-42.

37. Worthington P. Injury to the inferior alveolar nerve during implant placement: a formula for protection of the patient and clinician. Int. J. Oral Maxillofac. Implants 2004;19:731-4. 